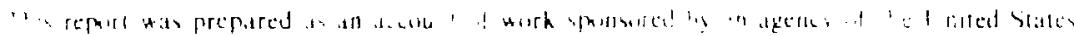

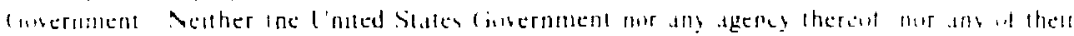

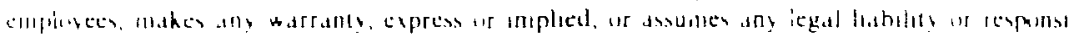

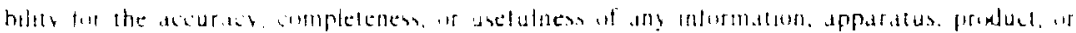

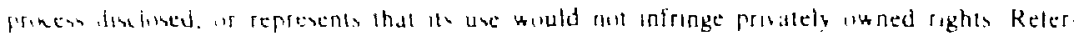

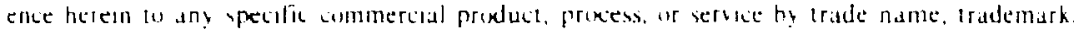

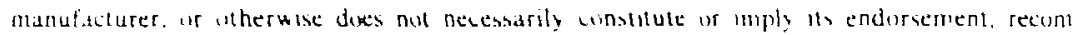
mendatun, os lawring by the linated states fwernment ur any agency thereut The vew and sponons of athors expressed herein do nut neceswarly state or reflect those of the

linited States fisvernment or any agenty thereul

\title{
The Microstructural and Microchemical Characterization \\ of Samples from the TMI-2 Core*
}

by

L. A. Neimark, R. V. Strain, I. E. Sanecki, and W. D. Jackson

Materials ard Components Technology Division

ARGONNE NATIONAL LABORATORY

Argonne, Illinots 60439

* Work supported by the U.S. Nuclear Regulatory Commission, 
The Microstructural and Microchemical Characterization of Samples from the TMI-2 Core

L. A. Nelmark, R. V. Strain, J. E. Sanecki, ind W. D. Jackson Argonne National Laboratory

Argonne, IL 60439

\begin{abstract}
Samples of materials from various regions of the TMI-2 reactor core and vessel have been examined at Argonne National Laboratory with a variety of microanalytical techniques. The purpose of these examinations is to characterize the microstructure and microchemistry of the materials so that their origin could be determined, their fission-product content evaluated, and their role in the accident scenario assessed. Macroscopic and microscopic composition inhomogeneities in melted fuel from different reactor locations indicate different cooling rates and solidification temperatures. The moblifty of molten fuel could have been enhanced by a low temperature eutectic in the Fe-Cr-O system. Stainless steel-clad Ag-In-Cd control rods could have failed from a eutectic reaction between the Zircaloy guide tubes and the cladding. Signiflcant concentrations of fissionproducts were not found, but their release from the fuel did not appear to be enhanced by gas-generated channels along grain boundaries.
\end{abstract}

INTRODUCTION

The TMI-2 accident presents an opportunity to assess the behavior of reactor materlals in synergisms never before possible in integral or separate effects testing. While the complexity of the accident scenario and the resulting multitude of materials interactions make a complete interpretation of the interactions virtually impossible, examination of core materlals can shed light on some of the materials-related phenomena that did occur and the environment in which they occurred.

Over the past four years Argonne National Laboratory has exalined materlals taken from a number of locations in the TMI-2 reactor. These samples included filtrate from the makeup water filters, lead screw segments, grab samples from the upper debris bed, debris from the lower plenum, "rocks" and agglomerates from core hores, fuel rod segments from the core pertphery and a core bore, a control rod segment from a core bore, and a poison rod $\left(\mathrm{B}_{4} \mathrm{C} / \mathrm{Al}_{2} \mathrm{O}_{3}\right)$ segment $\mathrm{From}$ a core bure. The objectlves of these examinations have been to (1) assess the physical states of the materials with respect to their environment, (2) Identify safety-related materials interactions, (3) evaluate fisston-product behavior with respect to release/retention mechanisms, and (4) contribute to the data base of materials behavior under severe accident conditions. These objectives generally have been fulfilled in the limited number of specimens that have been examined at ANL. However, this 
small number of specimens represents only a selective sampling of the core, and this contribution must be viewed together with the other work being conducted at the Idaho National Engineering Laboratory (INEL) and at forelgn laboratories in order to obtain a fuller plcture of the events that occurred in the TMI-2 core.

Emphasis in this paper will be placed on the microstructural and microchemical aspects of the specimen examinations. The general aspects of sample acquisition and the macroscopic features of TMI-2 core samples is being described elsewhere [1].

\section{SAMPLE LOCATIONS}

The samples described in this paper were recovered from the upper debris bed, the lower plenum debris bed, core bores, and peripheral fuel rods. The upper and lower plenum samples were pebble-size, from a fraction of an inch to 1-1/2 in. maximum dimension. The upper bed specimens came from various elevations at locations $\mathrm{E} 9$ and $\mathrm{H} 8$ and the lower bed specimens from the pertphery of the lower plenum. Core bore samples sent to ANL came from $a$ number of locations and in a number of forms. A fuel rod segment came from the 4-15 in. elevation (from the bottom of the core) from central core position K9. A control rod segment came from the 2-20.5 in. elevation from position N12. What is described as a homogeneous rock sample came from position 68 somewhere from the central core region. An agglomerate sample came from the 65 in. elevation from position D8. An agglomerate sample is one that contains both molten material and identifiable rod components.

\section{EXAMINATION METHODS}

The principal examination tools have been optical metallography, scanning electron microscopy in the back-scattered electron image mode (BSE), energydispersive X-ray sfactroscopy (EDS), electron milcroprobe analysis (EMP), scanning Auger microprobe analysis (SAM), and beta-gamma autoradiography. Gamma spectroscopy has been used to a limited extent.

Because of the muiti-component nature of all the samples, optical metallography had limited utility in differentiating the microstructural characteristics. The SEM/BSE images proved to be extremely valuable in delineating phases and their relative acomic numbers. Furthermore, if the specimen activity was low enough, the composition of the phases could be identified immediately by EDS. For specimens of high activity, the compositions were determined by EMP analysis. The SAM was used primarily to confirm the presence of oxygen, a capability the other instruments did not have. Autoradiography was used to locate areas of high activity in the search for fission products. Gama spectroscopy was used to qualitatively identify the principal activity peaks in a specimen. 


\section{Molten Structures}

Molten fuel was found in samples examined from all locations: upper debris bed, lower plenum, the core bore rock, and the core bore agglomerate The microstructures bore both similarities and disimilarities that reflect on the nature and characteristics of the materials.

The upper and lower debris bed samples consisted principally of equiaxed primary grains of $\mathrm{U}-\mathrm{Zr}-\mathrm{O}$ with minor impurities of $\mathrm{Fe}, \mathrm{Ni}, \mathrm{Cr}$ and $\mathrm{Al}$. The grain boundaries consisted of eutectic phases of $\mathrm{Fe}, \mathrm{Cr}, \mathrm{Al}$ and accassionally Ni. Typical inicrostructures are shown in Fig. 1. A eutectic composition occurs in the $\mathrm{FeO}-\mathrm{Cr}_{2} \mathrm{O}_{3}$ system at about $1350^{\circ} \mathrm{C}$ and 97 a/o FeO [2]. This is some $1200^{\circ}$ lower than the solidus temperatures in the $\mathrm{UO}_{2}-\mathrm{ZrO}_{2}$ system. Such a wixture would retain its fluidity at temperatures significantly below the solidus of tha $\mathrm{UO}_{2}-\mathrm{ZrO}_{2}$ primary grains. This fluidicy would have assisted the "melt" in relocating to the lower plenum.

The composition of the primary U-Zr-O grains in the upper and lower plenum samples was not determined quantitatively because of the lack of appropriate standards. However, differences in the $U$ and $Z r$ contents were discerned by the peak helght zatios of the EDS analyses and by the shading contrasts in the BSE images. The indicators showed that the lower plenum samples were not homogeneous on efther the macroscopic or microscopic levels. The macroscopic areas of slightly differing $U$ and $Z r$ contents were also characterized by their pore miphology as shown in Fig. 2. Higher Ucontent areas contained pores with a maximum diameter of $-0.2 \mathrm{~mm}$, while higher $Z_{r}$-content areas contained pores with diameters greater than -0.5 m. This difference is attributed to the lower solidus temperature of the higher $\mathrm{Zr}$ content areas leading to gas mobillty in molten fuel over a greater temperature range.

On the microscopic level the primary U-Zr-O grains showed a tendency to transform into U-rich and Zr-rich phases beginning at the grain boundaries and moving into the grains as shown in Fig. 3. This transformation was more advanced in the lower plenum specimens than in those from the upper debris bed. Also, the grain size of the lower plenum spectmens was significantly larger than that in the upper debris specimens, $-20 \mu$ compared to $-100 \mu$ (see Fig. 1). Both the grain size and the degree of transformation indicate that the lower plenum materlal cooled at a slower rate than the upper debils material.

A dendritic structure of U-Zr-O grains in a matrix of Fe-Cr-O eutectic was found surrounding most of the large pores and in one case a small pore area of the lower plenum specimens. These reglons were obviously the last to solidify and they were the only areas where non-oxidized metal inclustons of $\mathrm{Ag}, \mathrm{Ni}, \mathrm{Sn}$, and the fission products $\mathrm{Ru}$ and $\mathrm{Te}$ were found in these samples. In general, the amount of $N i$ found in the upper and lower debris samples was considerably less than would be expected from its content in stainless steel and Inconel and the substantial arounts of $\mathrm{Fe}$ and $\mathrm{Cr}$ that were found. It was 


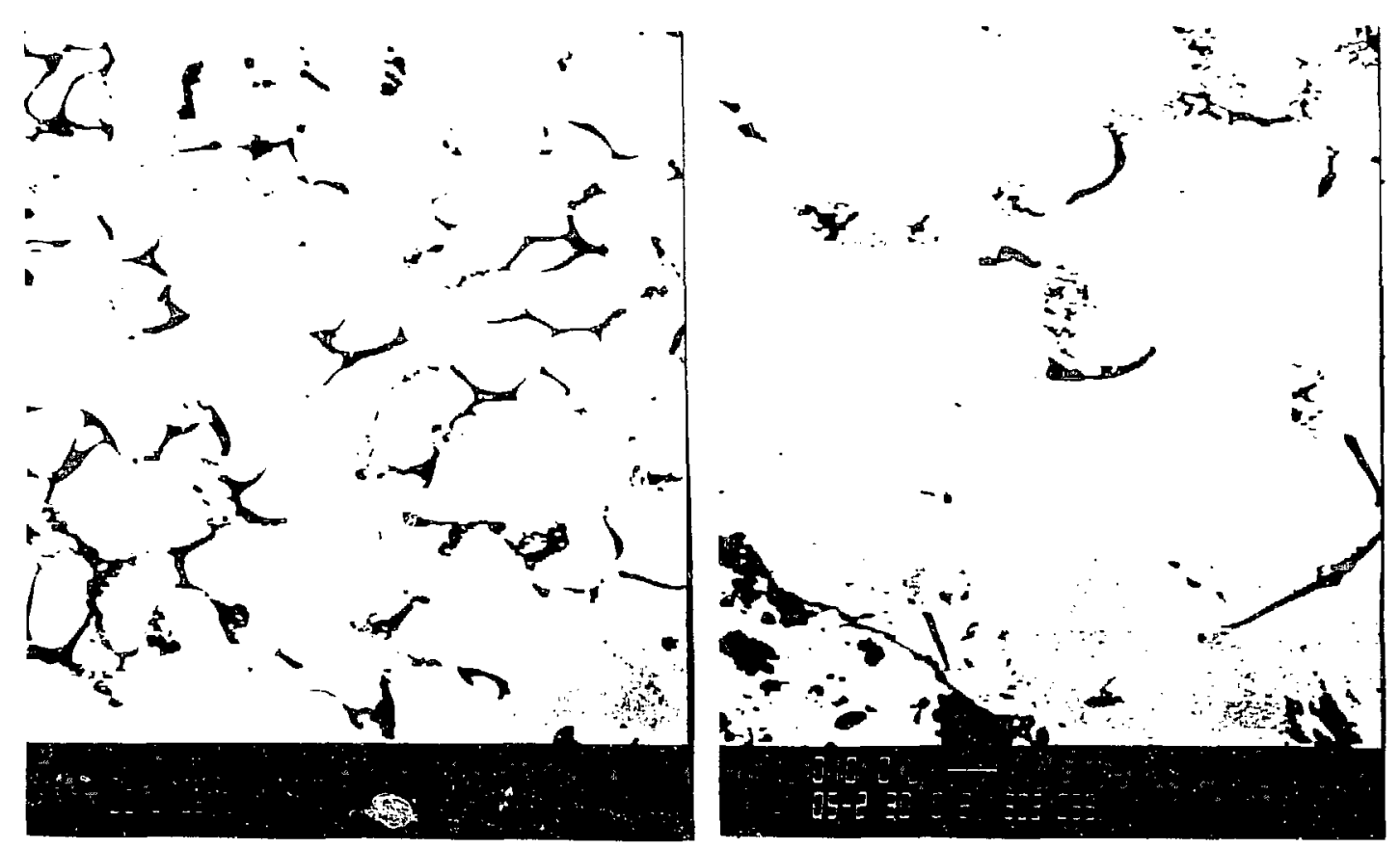

Figure 1. Molten fuel structures (SEM-BSE) from upper debris bed (left) and lower plenum ( $r$ lght).

$500 \mathrm{x}$

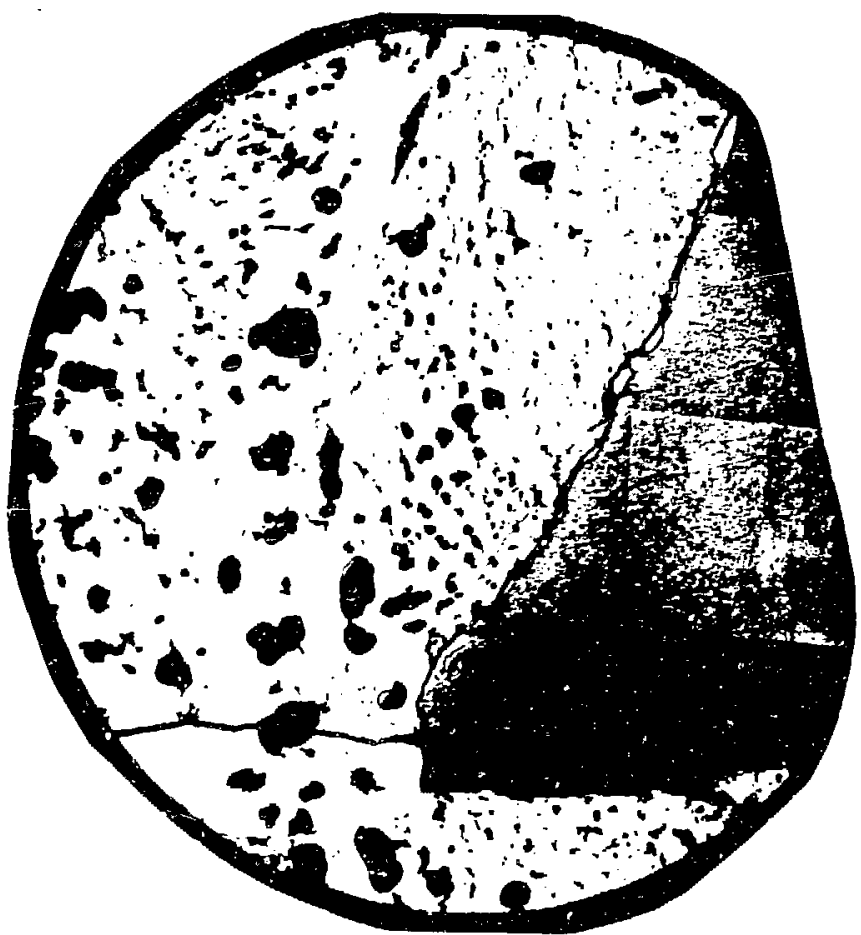

Figure 2. Molten fuel structure of lower plenum debris showing large and small pore regions of somewhat different $U$ and $Z r$ concents. MCT No. 238928A 


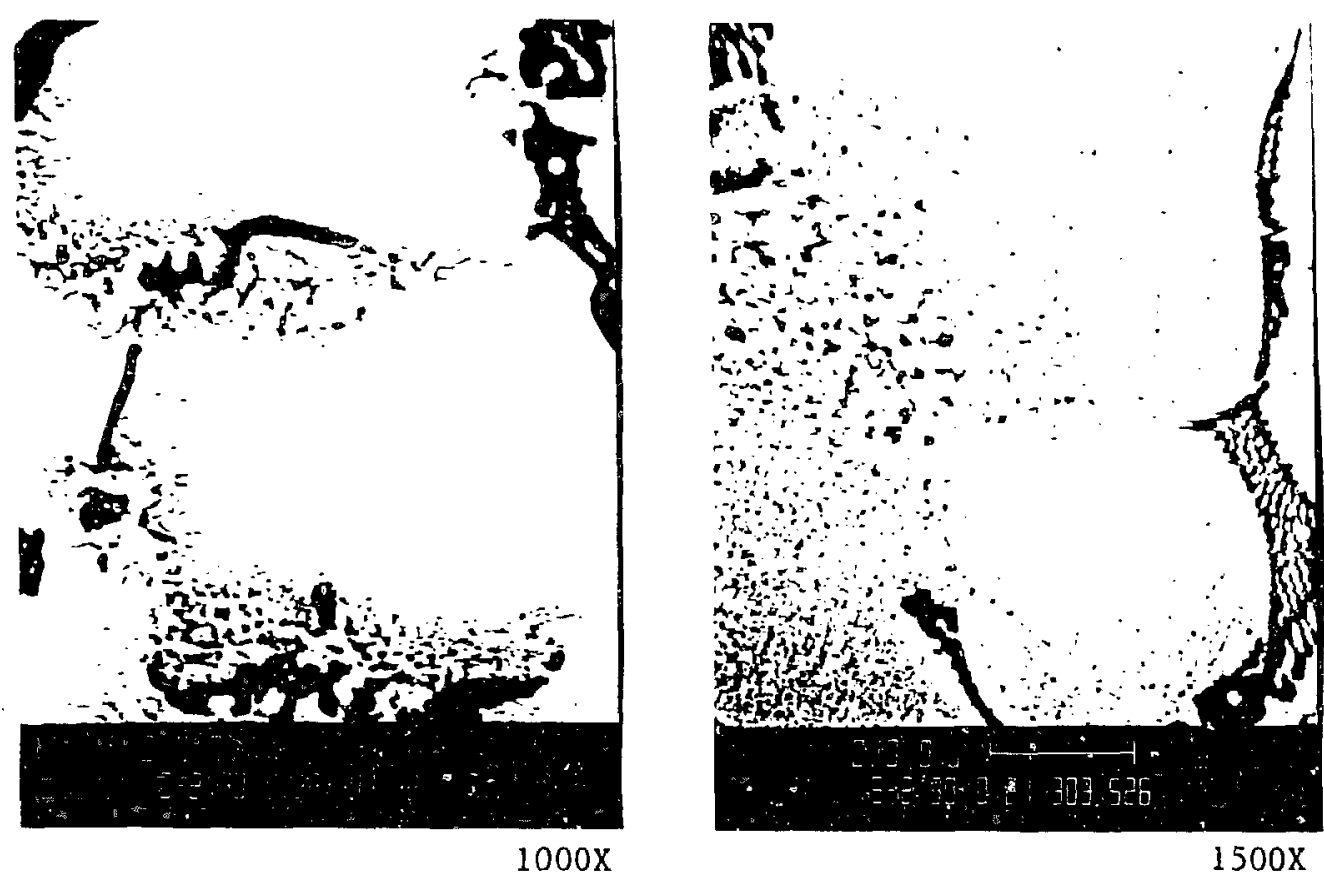

Figure 3. SEM-BSE images showing development of U-rich (11ght) and Zr-rich (gray) phases in structures from lower plenum melt.

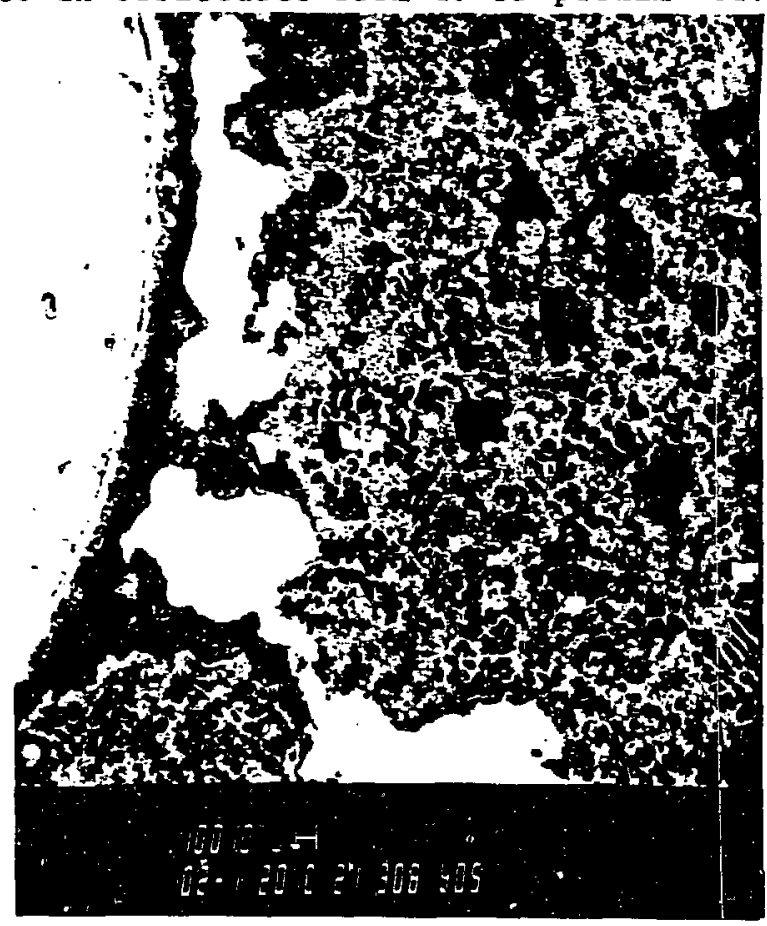

Figure 4. SEM-BSE image of agglomerate structure showing fuel pellet (left), $\mathrm{UO}_{2}-\mathrm{Zrc}$ reaction layer, molten $\mathrm{Ag}$-In masses, and dendritic structure of molten structural materials. 
concluded that the molten structures of the upper and lower debris beds consist principally of oxidized material with only minor amounts of nonoxidized core materials. These latter elements apparently were fluid at lower temperatures and flowed elsewhere in the reactor structure.

The microstructure of the once-molten core bore rock was homogeneous in its heterogeneity. The structure consisted almost totally of two-phase transformed $U-Z_{r}-0$ grains, $50-100 \mu$ diameter pores, and some areas of Fe-Cr-O eutectic. Occasionally, singular metal inclustons of $\mathrm{Ag}$ or $\mathrm{Ni}-\mathrm{Sn}$ were found in the large pores. The most significant differences from the upper and lower debris structures was the larger grains, greater extent of phase cransformation, and the absence of the Fe-Cr-O eutectic phase from the grain boundaries of the rock. These differences all indicate a longer time at elevated temperature.

The agglomerate sample that was examined consisted of a fractured $\mathrm{UO}_{2}$ pellet totally surrounded by a mixture of molten, mainly non-fuel core materials. An area of this structure is shown in Fig. 4. What appears to be clading in a molten state next to the pellet is actually masses of $\mathrm{Ag}-\mathrm{In}$, sans $\mathrm{Cd}$, with some $\mathrm{Sn}$. The thin layer in contact with the fuel is a $\mathrm{Zr}^{-\mathrm{UO}_{2}}$ reaction product. The balance of the molten structur 2 was significantly different from those previously described. The principal grains were dendritic rather than equiaxed and consisted of $\mathrm{Fe}, \mathrm{Ni}$, and $\mathrm{Cr}$. The lightcolored mairix surrounding the dendrites is made up principally of $\mathrm{Ni}, \mathrm{Sn}$, and $\mathrm{Zr}$ with lesser amounts of $\mathrm{Fe}, \mathrm{Cr}, \mathrm{U}$, and $\mathrm{In}$. The amount of $\mathrm{Ni}$ in this structure, in excess of its relative amount in stainless steel, constitutes the greatest concentration of $\mathrm{Ni}$ found in any of the molten structures examined. It is possible that the high concentration of $N i$ at this elevation is due to the proximity of a molten Inconel $718 \mathrm{spacer}$ grid. Nonetheless, it would appear that $\mathrm{N} 1$ tends to segregate from regions of molten $\mathrm{U}-\mathrm{Zr}-0$ and goncentrates with $\mathrm{Sn}$ from the Zircaloy. Because the sample was very high in ${ }^{60}$ Co activity, EDS analytical data could not be used to identify the phases and the EMP was used instead.

\section{Materials Interactions}

The agglomerate sample, described above, exhibited a reaction layer between the $\mathrm{UO}_{2}$ pellet and the molten Zircaloy cladding. The reaction interaface, shown in Fig. 5, shows a number of different phases indicating the dissolution stages of the reaction. This phase also penetrated the major cracks in the fuel but did not appear to further react with the fuel. Apparently the contact time at the elevated temperatures was short at this elevation.

The fuel rod segment from the central core showed no interaction between the $\mathrm{UO}_{2}$ and the Zircaloy cladding. The cladding structure clearly showed transformation to the B-phase indicating temperatures on the order of $1000^{\circ} \mathrm{C}$. The transformation in the cladding was incomplete around the circumference providing a rather sharp temperature demarcation at about $950^{\circ} \mathrm{C}$. The fuel structure in this segment, shown in Fig. 6, was totally finegrained and contained small metallic inclusions. From SEM-BSE images it was 


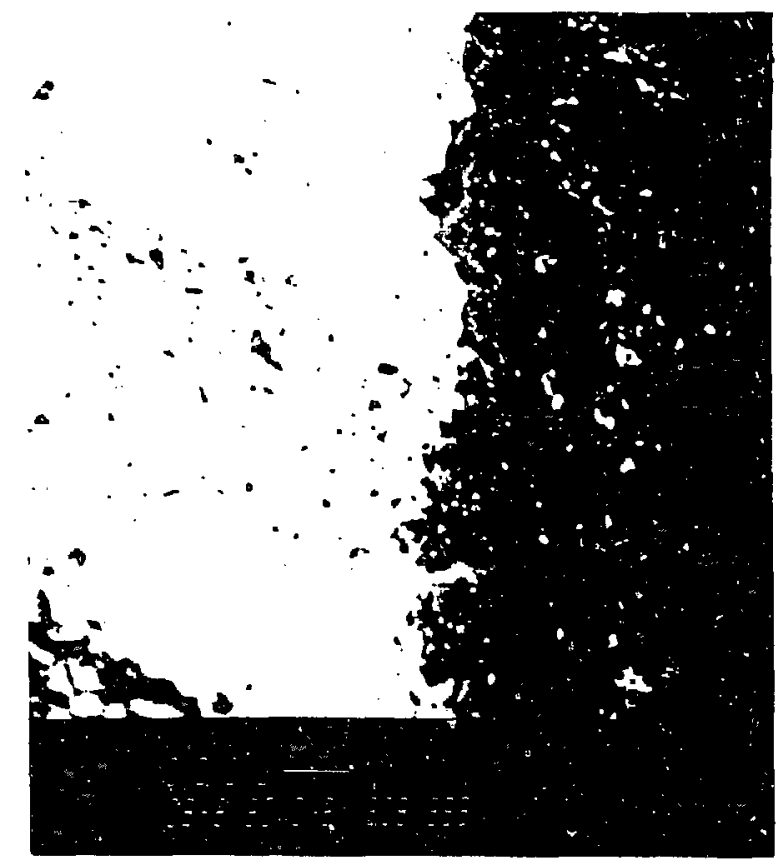

Figure 5. SEM-BSE image of $\mathrm{UO}_{2}$ pellet (light) and Zircaloy cladding (dark) in agglomerate specimen. Particles of $\mathrm{UO}_{2}$ are seen in various stages of dissolution in the $\mathrm{Zr}(0)$.

$800 \mathrm{X}$

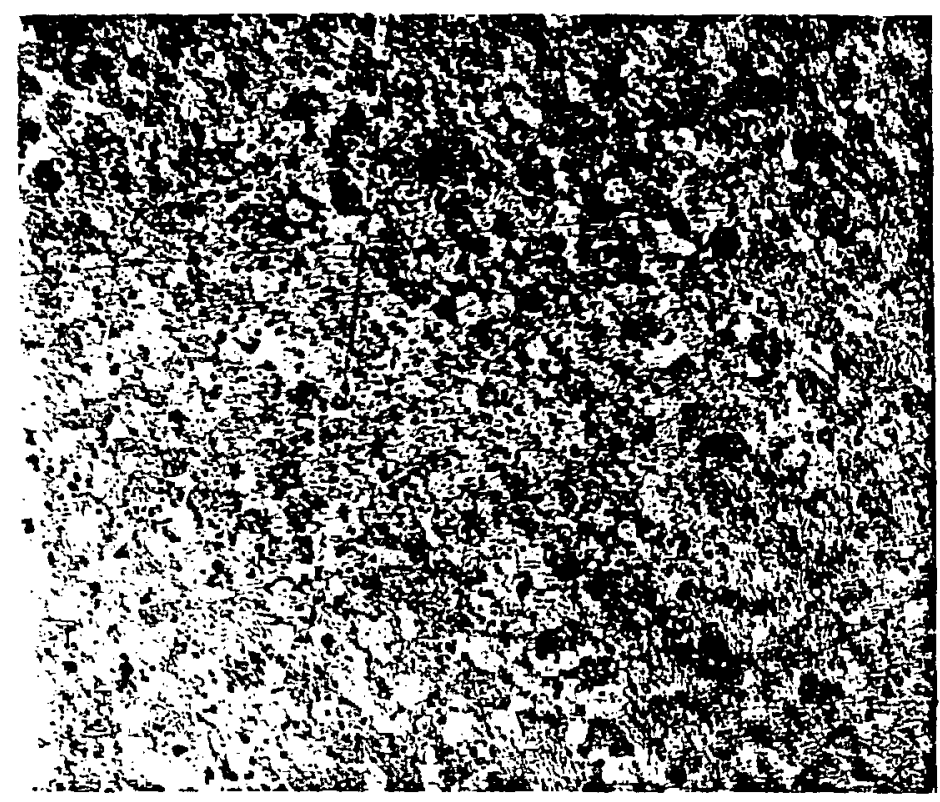

Figure 6. Optical image of etched $\mathrm{UO}_{2}$ fuel in rod segment from $\mathrm{K} 9$. White inclusions are probably non-oxidized Mo. MCT No. 243861 
determined that the inclusions were not Eree uranium but an element of lower atomic number than $\mathrm{UO}_{2}$. It is likely that the inclusions are non-oxidized Mo indicating that this particular fuel had an $0 / M$ ratio very close to 2.00. (At higner $O / M$, the $M o$ would have oxidized and gone into solution with the $\mathrm{VO}_{2}$. At a lower $0 / M$, free $U$ would have been present.)

The most interesting materials interaction found was between the Zircaloy guide tube and the stainless steel cladding of a $\mathrm{Ag}-\mathrm{In}-\mathrm{Cd}$ control rod. The piece examined, shown in Fig. 7, apparently was at a significant temperature transition boundary. The intact Zircaloy guide tube in the lower part of the segment hac transformed to the $\beta$-phase $\left(>1000^{\circ} \mathrm{C}\right)$ while $0.5 \mathrm{in}$. above it the Zircaloy formed a eutectic with the stainless steel cladding $\left(935-960^{\circ} \mathrm{C}\right)$ as shown in Fig. 8. There was no reaction between the $\mathrm{Ag}-\mathrm{In}-\mathrm{Cd}$ and the stainless steel. at either elevation. A molten structure containing $\mathrm{Fe}, \mathrm{Ni}, \mathrm{Cr}, \mathrm{Zr}, \mathrm{Ag}$, $\mathrm{In}$, and some $\mathrm{Cd}$ was found between the Zircaloy guide tube and the cladding in the lower part of the segment. This material apparently had flowed down from above after the $\mathrm{Zr}-\mathrm{Fe}-\mathrm{Ni}$ eutectics breached the cladding and the $\mathrm{Ag}-\mathrm{In}-\mathrm{Cd}$ had become molten, not necessarily at the same elevation.

\section{Fission-Product Behavior}

Based on the qualitative gamma spectroscopy, ${ }^{137} \mathrm{Cs},{ }^{106} \mathrm{Ru} / \mathrm{Rh}$, and ${ }^{125} \mathrm{Sb}$ were the only fission products present in detectable quantities, although isolated $\mathrm{Ru}$ and Te inclusions were found by EDS. (The principal activity in the samples was ${ }^{6}$ Co.) Autoradiography Indicated that the radioactive species were located principally adjacent to the pores in the molten structures. The finding of $\mathrm{Ni}$ inclusions in some of these pores suggests that much of the activity indicated in the autoradiographs is ${ }^{60} \mathrm{Co}$. However, condensation of Cs-containing species in the pores is possible. (SEM examination of the core bore rock did find small spherical deposits of low atomic number material that could have been vapor-deposited in the pores; an elemental analysis was not possible, however, because of the geometry.)

Both the Ru and Te concentrations were found combined or associated with $\mathrm{Ni}$ and $\mathrm{Sn}_{n}$ in metal inclusions in pores or last-to-freeze dendritic areas. Quantitatively, it is not possible to assess whether such association would significantly retard release of these fission products.

Fractographic examination of one small fuel area in the agglomerate sample, shown in Fig. 9, indicated that there was no significant coalesence of fission-gas bubbles or channel formation on grain boundaries that could have been pathways for fission-product release. Such areas might exist in fuel

that was closer to the molten center of the core. However, because of the low Euel burnup and low gas inventory such pathways in what would apparently be a small volume of the core would not be expected to contribute significantly to fission-product release.

CONCLUSIONS

Conclusions drawn from these examinations must obviously be tempered by the meager sampling statistics when generalities are made. However, having 


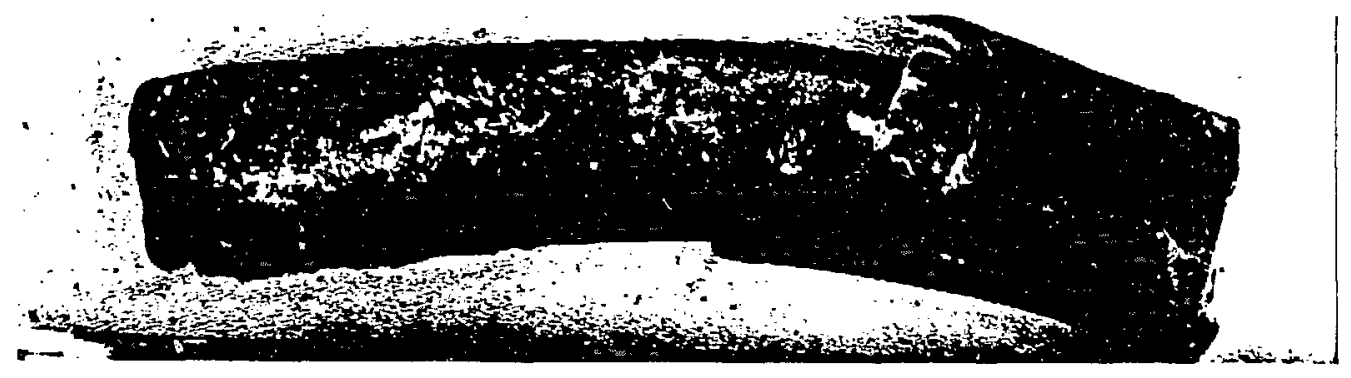

Figure 7. Segment of Ag-In-Cd control rod (top to left) showing remnant of Zircaloy guide tube (right) and surface of reacted stainless steel cladding (left).

MCT No. 243745

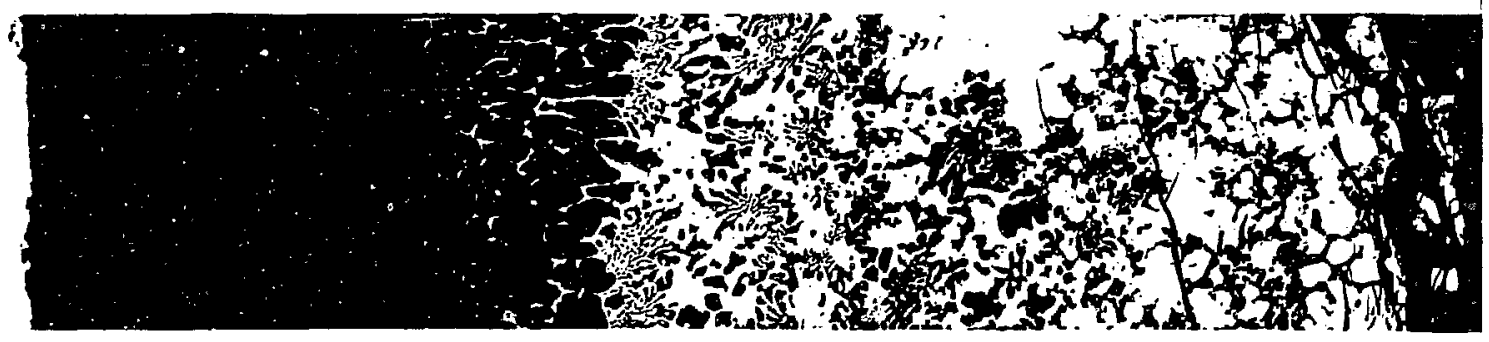

Figure 8. SEM-BSE image of eutectic reaction zones (2) between 304 stainless steel (dark) and Zircaloy (gray). The Ag-In-Cd/SS interface is at the far left and the surface of the "cladding" in Fig. 7 is at the far right.

MCT No. 243798 


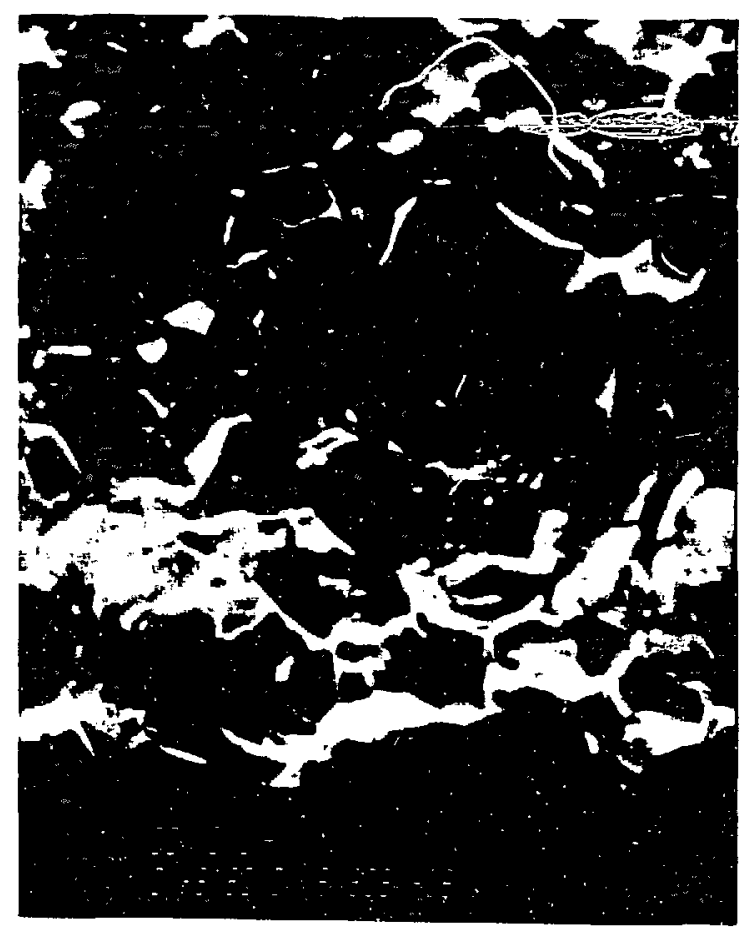

Figure 9. SEM fractograph from $\mathrm{UO}_{2}$ fuel in agglomerate specimen showing absence of fission gns bubbles or channels on grain boundaries. l000X 
some data is at least a starting point for broadening our knowledge. Therefore, the following is offered in that vein.

1. The microstructures of molten materlals examined from different reactor locations indicate different cooling rates and solidification temperatures. This is based on macroscopic and microscopic compositional lnhomogeneities in the structures and differing grain sizes and morphologies.

2. Molten material likely reached the lower plenum assisted by a lowinelting $\left(\sim 1300^{\circ} \mathrm{C}\right)$ eutectic phase of $\mathrm{Fe}-\mathrm{Cr}-\mathrm{Al}-\mathrm{O}$ in the melt that provided fluidity.

3. The molter areas basically consist of oxides with random inclusions of non-oxidized materials such as $\mathrm{Ni}, \mathrm{Sn}, \mathrm{Ag}$, $\mathrm{In}$, some $\mathrm{Cd}$ and fission-product $\mathrm{Te}$ and $\mathrm{Ru}$.

4. Stainless steel-clad, Ag-In-Cd control rods could have failed from a eutectic reaction between the Zircaloy guide tubes and che cladding at $935-960^{\circ} \mathrm{C}$.

5. Fission-product release from unmelted fuel was not enhanced by appreciable pathway development in grain boundaries.

6. Although some metallic $\mathrm{Te}$ and Ru were found combined with $\mathrm{Ni}$ and Sn inclusions, the effect of this alloying on retarding fission-product release is not readily quantifiable.

\section{$\underline{\text { ACKNOWLEDGEMENTS }}$}

This paper was made possible by the diligent efforts of D. Donahue, F. Pausche, and C. Gebo at ANL's Alpha-Gamma Hot Cell Facility. The work was supported by the U.S. Nuclear Regulatory Commission.

\section{REFERENCES}

1. C. S. Olsen, D. W. Akers, and R. McArdell, "TMI-2 Core Bore Examination Results," this conference.

2. E. M. Levin, C. R. Rotbins, and H. F. McMurdie, Phase Diagrams for Ceramists, Am. Ceram. Soc., Columbus, OH, Vol. 2, p. 27, 1969. 